\title{
Case Resort
}

\section{Laparoscopic excision of large omental cyst at department of pediatric surgery in Sanglah general hospital, Bali, Indonesia}

\author{
A. A. A. Oka Kasuma Dewi, Kadek Deddy Ariyanta*
}

Department of General Surgery, Sanglah Hospital, Faculty of Medicine Udayana University, Denpasar, Bali, Indonesia

Received: 15 September 2019

Accepted: 19 September 2019

\section{*Correspondence:}

Dr. Kadek Deddy Ariyanta,

E-mail: deddyariyanta@yahoo.com

Copyright: (C) the author(s), publisher and licensee Medip Academy. This is an open-access article distributed under the terms of the Creative Commons Attribution Non-Commercial License, which permits unrestricted non-commercial use, distribution, and reproduction in any medium, provided the original work is properly cited.

\begin{abstract}
Omental cyst is rare. All conditions most likely being of congenital or benign neoplastic lymphatic origin. Patients with Omental cysts usually present with abdominal distention and a painless abdominal mass. The most common physical finding of an omental cyst is a freely movable abdominal mass. The diagnostic procedure include CT scans. Complete excision by open or laparoscopically of the cysts is considered as the treatment of choice. Recurrence and malignant deterioration of omental cysts are rare. A case report of a large omental cyst which had been laparoscopically-treated using morcellator. Laparoscopic morcellation is a technique used in gynecological surgeries such as hysterectomy and myomectomy to remove uteri and uterine fibroids (leiomyomas) through a small abdominal incision. Authors present a case of 3 year old female with pre-operative assessment tumor intra-abdominal suspect abdominal cyst. Subsequently, laparoscopic resection of omental cyst with morcellator was performed. The histopathological report was omental cyst. Omental cysts are rare, but can be shown to have atypical abdominal symptoms and radiologic findings, so clinicians must keep in mind that omental cysts causing abdominal symptoms can be misdiagnosed as simple ovarian cysts of inflammation. Omental cysts can be removed safety laparoscopically with morcellator without bowel or vessel injury.
\end{abstract}

Keywords: Abdominal mass, Laparoscopic, Morcellation, Morcellator, Omental cyst

\section{INTRODUCTION}

Omental cyst is rare, the incidence is approximately 1 per 105,000 admissions to general hospital and 1 per 20,000 admissions to pediatric hospitals. ${ }^{1}$ It is a rare lesion occurring primary during childhood and young adulthood. It is closely related to mesenteric and retroperitoneal cyst, all conditions most likely being of congenital or benign neoplastic lymphatic origin. ${ }^{2}$ the omental only about 150 cases reported till now, $25 \%$ of which presented in children less than 10 years of age. Some Japanese literature indicate that omental cysts develop more frequently in man than in women whereas in Western countries there is a female predominance. The first report of an omental cyst was published in 1852 by Gairdner. $^{2}$

Patients with omental cysts usually present with abdominal distention and a painless abdominal mass. The most common physical finding of an omental cyst is a freely movable abdominal mass. The diagnostic procedure includes computed tomography (CT) scans. Complete excision of the cysts is considered as the treatment of choice. Recurrence and malignant deterioration of omental cysts are rare. Authors report a case of a large omental cyst which had been laparoscopically treated using morcellator. 


\section{CASE REPORT}

This $3^{\text {th }}$ year old girl presented at our department with abdominal distention, intraabdominal mass, and painless. She had the mass for 8 months prior to admission.

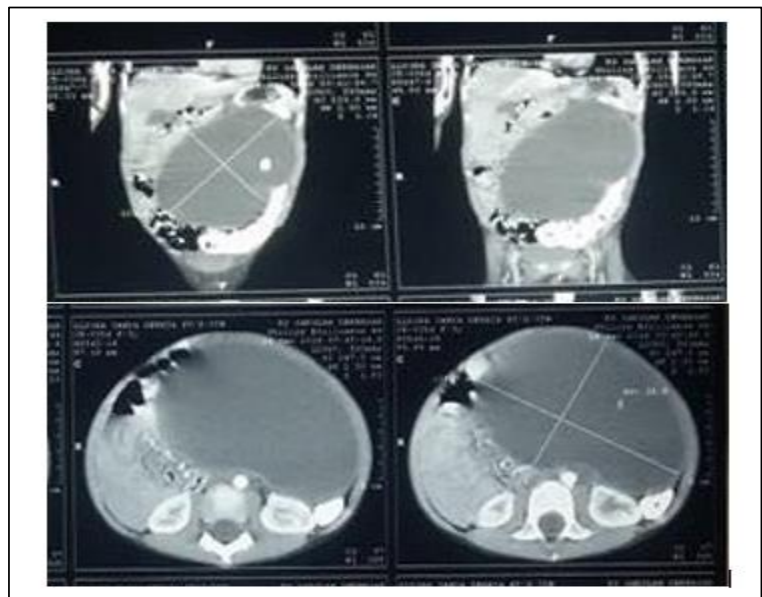

Figure 1: CT Scan demonstrating cystic lesions $\emptyset 18 \mathrm{~cm}$.

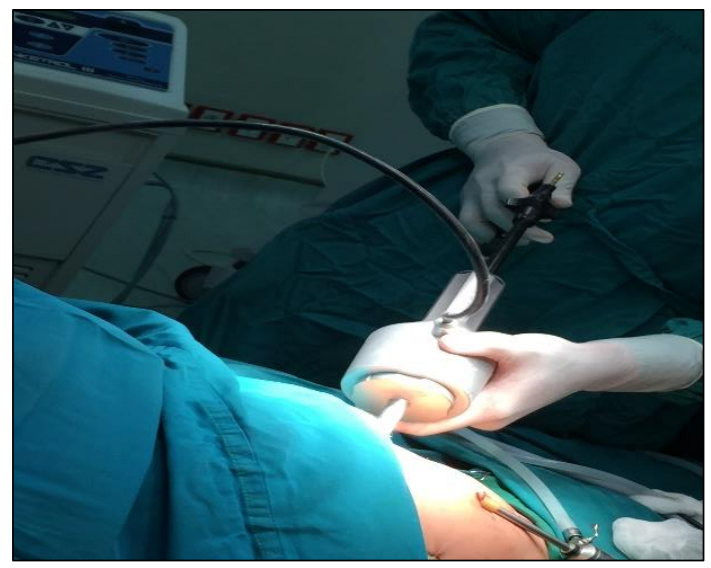

Figure 2: Laparoscopic use morcellator to remove the cyst.

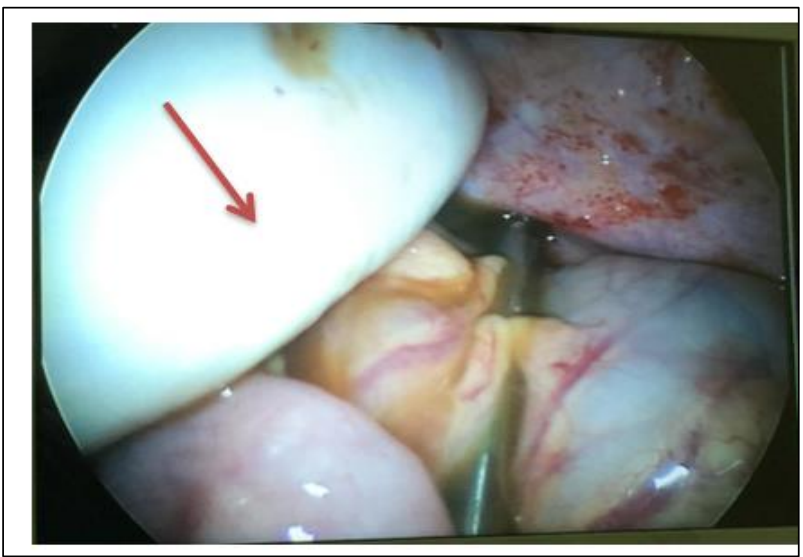

Figure 3: the large omental cyst and suction the fluid inside the cyst.

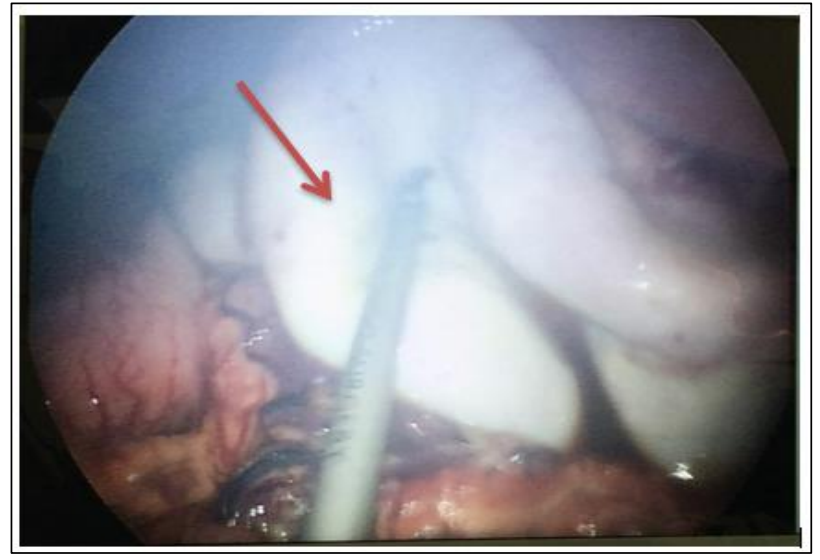

Figure 4: the large omental cyst and suction the fluid inside the cyst. (continue).

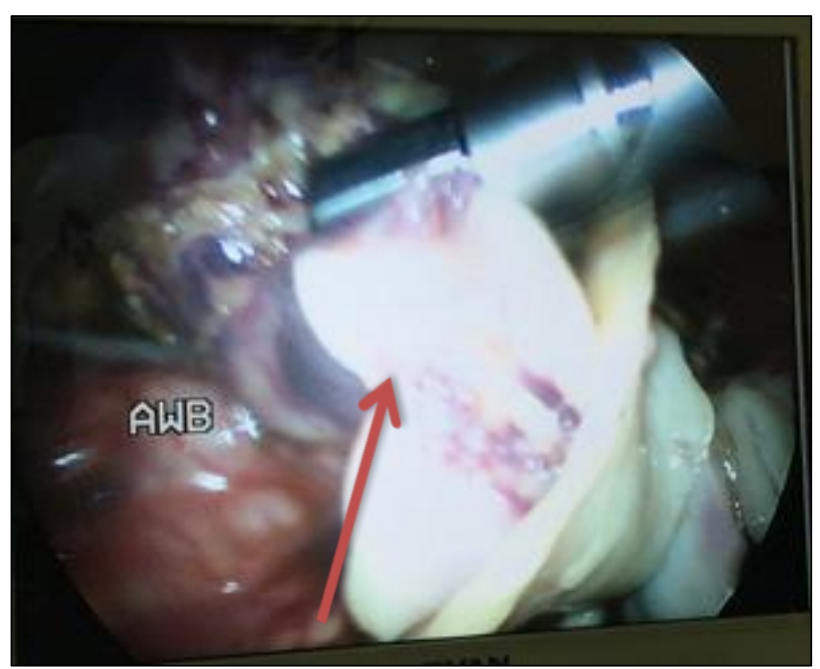

Figure 5: the morcellator cut the cyst with rotating blades.

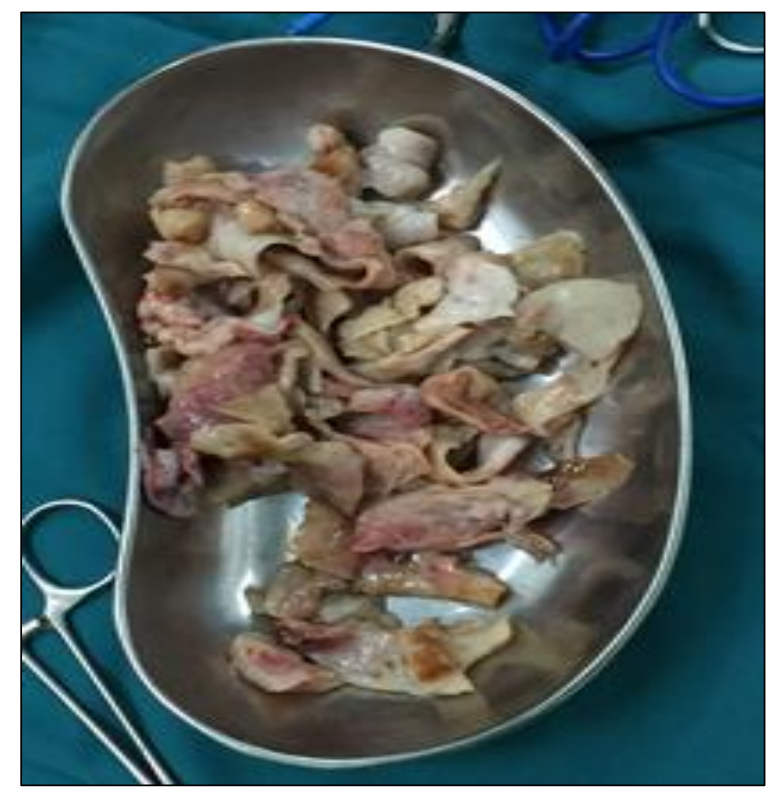

Figure 6: the small fragments from the cyst. 
The patient was in good condition. The findings of the gastroenterology status were within normal limit. From palpation examination in abdomen showed palpable

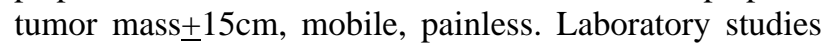
were within normal limit. Authors did CT Scan abdomen and authors found cystic lesions with $\emptyset 18 \mathrm{~cm}$ (Figure 1).

The patient underwent laparoscopic resection with morcellator (Figure 2). The cyst was mobile and without enlargement on lymph nodes, were perform suction the fluid from the cyst, dissected the omental stalk easily by harmonic, followed by morcellator without any significant bleeding (Figure 3, Figure 4, Figure 5, figure 6). The cyst was filled with serous fluid. The histopathological report was omental cyst. The patient was recovered uneventfully. There were no early complications after the surgery and the patients did well postoperatively, and post-operative hospital stay only for 3 days.

\section{DISCUSSION}

Omental cyst is rare, the incidence is approximately 1 per 105,000 admissions to general hospital and 1 per 20,000 admissions to pediatric hospitals. ${ }^{1}$ It is a rare lesion occurring primary during childhood and young adulthood. It is closely related to mesenteric and retroperitoneal cyst, all conditions most likely being of congenital or benign neoplastic lymphatic origin. ${ }^{2}$

In 1852 Gairdner first described an omental cyst, defined as a cyst within the lesser or greater omentum with an endothelial lining, representing one-third to one-tenth of mesenteric cysts. The first excistion of an omental cyst was performed by Tillaux in 1880, in 1993, Mackenzie et al. described the first laparoscopic complete resection of a large mesenteric cyst, demonstrating the feasibility of this technique. ${ }^{3}$

Patients with an omental cyst do not have typical symptoms, such as vague abdominal pain and distension, vomiting, or nausea; some patients are asymptomatic. The cysts are usually found accidentally on CT or MRI.

The exact diagnosis of omental or mesenteric cyst is not easy before operation. Acute symptoms are secondary to complications of obstruction, rupture, hemorrhage, or infection. Gynecologists must keep in mind the fact that the patient presenting with abdominal pain and a cystic lesion in the pelvic cavity has a possibility of gynecologic lesion, as well as mesenteric or omental cyst. ${ }^{3}$

The differential diagnosis of omental cysts are mesenterial cyst, intestinal duplication cyst, ovarian cyst, choledochal cyst, pancreatic, splenic, or renal cyst, hydronephrosis, cystic teratoma, dermoid, hydatid cyst, ascites. Modern imaging studies can usually determine the organ where cystic lesions within the abdominal cavity originate. ${ }^{1}$
The standard therapy of omental cysts is complete resection via laparotomy or laparoscopy. The treatment is surgical and includes total removal of a lesion; invasion to potentially resectable intra-abdominal structures, such as the bowel, spleen, or pancreas is possible, but adhesions to vital structures can make resection hazardous or even impossible. But an intestinal resection is virtually never indicated. Omental cysts can always be removed without resecting the adjacent transverse colon or the stomach. ${ }^{3}$

In few cases, it can be difficult to dissect omental cysts safely from surrounding tissues without bowel or vessel injury because the stalk of the omentum is broadly connected to the cyst, which can widen the surgical range, leading to serious bleeding and injuries to the surrounding stomach or intestines. ${ }^{3}$ In this case, to resection the cyst is difficult because the large size of the cyst $(\varnothing 18 \mathrm{~cm})$ cover almost over surrounding stomach, authors can't see the other organ. Authors did cut the wall of the cyst and suction the fluid via laparoscopy, so Authors can see the other organ more clearly. Authors did not have to respect other abdominal structures and the omental cyst was clearly removed using the method via laparoscopy.

With the development of laparoscopy in the last decade, laparoscopic surgery has come to be preferred to laparotomy because it may result in less post-operative pain and analgesics, a shorter hospital stay, and earlier return to normal activity. No different posy-operative complication occur between laparotomy and laparoscopy. ${ }^{2}$ Laparoscopic morcellation is a technique used in gynecological surgeries such as hysterectomy and myomectomy to remove uteri and uterine fibroids (leiomyomas) through a small abdominal incision. ${ }^{4}$

The morcellators are tiny devices with rotating blades that break large tissue masses into small fragments. ${ }^{5}$ Tissue morcellation during gynecologic surgery has been widely practiced to facilitate removal of large uteri or uterine myomas through less invasive incisions than those used in a traditional laparotomy. ${ }^{6}$ The first electronic morcellator was introduction in $1993 .^{7}$ The power morcellator for gynecologic use was approved by the U.S Food and Drug Administration (FDA) in the 1990s. Broken down tissues are then vacuumed out of the body through the laparoscope. The technique allows surgeons to make incisions of less than 2 centimeters in size and remove fibroids and other tissue. These smaller entry points to the body mean doctors do not have to make large incisions through care stomach muscles. The transition to the smaller incisions as led to quicker patient recoveries, less post-operative pain and fewer wound complication. $^{5}$

Surgeons typically perform surgery using 2 morcellation techniques: laparoscopic and hysteroscopic. In laparoscopic morcellation, surgeons insert the drill-like device through a small incision in the abdomen from which they can shred and remove the tissue. ${ }^{6}$ 


\section{CONCLUSION}

Omental cyst is rare but can be shown to have atypical abdominal symptoms and radiologic findings, so clinicians must keep in mind that omental cysts causing abdominal symptoms can be misdiagnosed as simple ovarian cysts of inflammation. Omental cysts can be removed safety laparoscopically with morcellator without bowel or vessel injury. The laparoscopic procedure is not simple, but it is cosmetically superior, the transition to the smaller incisions as led to quicker patient recoveries, less post-operative pain and fever wound complication, a shorter hospital stay, and earlier return to normal activity.

Funding: No funding sources Conflict of interest: None declared

Ethical approval: Not Required

\section{REFERENCES}

1. Ricketts RR. Mesenteric and Omental Cysts. Pediatric Surg. 2012;7(91):1165-70.

2. Shackclford GD, McAlister WH. Cysts of the Omentum. Pediatr Radiol. 1975 Jun 13;3(3):152-5.

3. Lee KW, Oh YS, Han SY. Laparoscopic treatment of an omental cyst misdiagnosed as an adnexal cyst: a case report. J Women's Med. 2010;3(2):84-87.
4. Isakov A, Murdaugh KM, Burke WC, Zimmerman S, Roche E, Holland D, et al. A New Laparoscopic Morcellator Using an Actuated Wire Mesh and Bag. J Medical Devices. 2014; 8(3):011009-1-011009-7.

5. Youngberg, Barbara. Use of Power Morcellators: Minimizing Liability, Assuring Safety? A Beecher Carlson Publication. 2015.

6. Available at: http://www.beechercarlson.com/wpcontent/uploads/2015/02/Healthcare-NewsletterMorcellator_V2.pdf. Accessed 9 August 2019.

7. Motie MR, Asadi M. Large Omental Cyst: A Care Report and Review of the Literature. Acta Medica Iranica, 2011;49(10):690-3.

8. Singh SS, Scott S, Bougie O, Leyland N, Wolfman $\mathrm{W}$, Allaire C, et al. Technical update on tissue morcellation during gynaecologic surgery: its uses, complications, and risks of unsuspected malignancy. J Obstetr Gynaecol Canada. 2015 Jan 1;37(1):68-78.

Cite this article as: Dewi AAAOK, Ariyanta KD. Laparoscopic excision of large omental cyst at department of pediatric surgery in Sanglah general hospital, Bali, Indonesia. Int J Res Med Sci 2019;7:3949-52. 